\title{
PENGETAHUAN LANSIA TENTANG POSYANDU LANSIA DI DUSUN MANDUNG DESA SEMBUNG GEDE KECAMATAN KERAMBITAN KABUPATEN TABANAN TAHUN 2018
}

\author{
Ni Made Ari Febriyanti ${ }^{1,2}$, KarnovaTeresaPutri Naba ${ }^{1,2}$ \\ ${ }^{1}$ Program Studi DIII Kebidanan, ${ }^{2}$ Politeknik Kesehatan Kartini Bali \\ Korespondensi penulis: febriari98@yahoo.com
}

\begin{abstract}
Abstrak
Latar belakang dan tujuan: Lansia merupakan proses penuaan dengan bertambahnya usia individu yang ditandai dengan penurunan fungsi organ tubuh seperti otak, jantung, hati dan ginjal serta peningkatan kehilangan jaringan aktif tubuh berupa otot-otot tubuh. Posyandu lansia merupakan pusat kegiatan masyarakat dalam upaya pelayanan kesehatan pada lanjut usia. Penelitian ini bertujuan mengetahui pengetahuan lansia tentang posyandu lansia di Dusun Mandung Desa Sembung Gede Kecamatan Kerambitan Kabupaten Tabanan.

Metode: Penelitian ini merupakan penelitian deskriptif dengan pendekatan cross sectional. Jumlah sampel yang diambil 41 responden dengan tehnik pendekatan purposive sampling. Instrumen yang digunakan dalam penelitian ini adalah pengisian kuesioner dengan 15 pernyataan sesuai dengan konsep teori tentang pengetahuan yang hendak diukur. Teknik analisa pada penelitian ini menggunakan analisa univariat dimana masing-masing variabel akan dideskripsikan berdasarkan hasil persentase.

Hasil: Pengetahuan lansia tentang posyandu lansia, sebagian besar dua responden (67\%) memiliki pengetahuan kurang berasal dari pendidikan dasar, Sebagian besar dua responden (67\%) memiliki pengetahuan kurang berumur 75-90 tahun dan seluruh responden yaitu tiga (100\%) memiliki pengetahuan kurang untuk mendapatkan sumber informasi dari media elektronik.

Simpulan: Sebagian besar pengetahuan lansia kurang tentang posyandu lansia, sebagian besar lansia memiliki pengetahuan kurang berusia 75-90 tahun dan seluruhnya memiliki pengetahuan kurang mendapatkan sumber informasi dari media elektronik.
\end{abstract}

Kata kunci: Lansia, Pengetahuan, Posyandu Lansia

\section{Pendahuluan}

Menua bukan suatu penyakit tetapi merupakan proses yang mengakibatkan perubahan yang kumulatif yaitu proses menurunnya daya tahan tubuh dalam menghadapi rangsangan dari dalam dan luar tubuh yang berakhir dengan kematian (Nugroho, 2012). Menurut World Health Organization (Jayanti, 2017) ada empat kriteria lansia yang dilihat berdasarkan umur yaitu: usia pertengahan (middle age) adalah 45-59 tahun, lanjut usia (elderly) adalah 6074 tahun, lanjut usia tua (very old) diatas 90 tahun.
Masalah kesehatan lansia berdasarkan Badan pusat Statistik dan Susenas tahun 2012 tertinggi adalah batuk $(17,81 \%)$ dan pilek $(11,75 \%)$ serta jenis keluhan lainnya yang merupakan efek dari penyakit kronis, seperti asam urat, darah tinggi, rematik, darah rendah, dan diabetes. Seiring dengan semakin meningkatnya populasi lanjut usia, pemerintah telah merumuskan berbagai kebijakan pelayanan kesehatan lanjut usia yang ditujukan untuk meningkatkan derajat kesehatan dan mutu kesehatan lanjut usia seperti pelayanan ditingkat masyarakat adalah Posyandu Lansia, pelayanan kesehatan 
lansia tingkat dasar adalah Puskesmas, dan pelayanan kesehatan tingkat lanjutan adalah Rumah Sakit (Mujahidullah, 2012).

Masalah kesehatan lansia berdasarkan Badan pusat Statistik dan Susenas tahun 2012 tertinggi adalah batuk $(17,81 \%)$ dan pilek $(11,75 \%)$ serta jenis keluhan lainnya yang merupakan efek dari penyakit kronis, seperti asam urat, darah tinggi, rematik, darah rendah, dan diabetes. Seiring dengan semakin meningkatnya populasi lanjut usia, pemerintah telah merumuskan berbagai kebijakan pelayanan kesehatan lanjut usia yang ditujukan untuk meningkatkan derajat kesehatan dan mutu kesehatan lanjut usia seperti pelayanan ditingkat masyarakat adalah Posyandu Lansia, pelayanan kesehatan lansia tingkat dasar adalah Puskesmas, dan pelayanan kesehatan tingkat lanjutan adalah Rumah Sakit (Mujahidullah, 2012). Berdasarkan penjelasan di atas maka peneliti tertarik untuk melakukan penelitian tentang "Pengetahuan Lansia Tentang Posyandu Lansia di Dusun Mandung, Desa Sembung Gede, Kecamatan Kerambitan, Kabupaten Tabanan Tahun 2018".

\section{Metode Penelitian}

Penelitian ini merupakan penelitian deskriptif dengan pendekatan cross sectional. Populasi yang digunakan berjumlah 162 orang dengan responden berjumlah 41 orang.
Instrumen yang digunakan dalam pengumpulan data penelitian adalah kuesioner. Dalam pernyataan yang diberikan yaitu pengetahuan lansia tentang posyandu lansia sebanyak 15 pernyataan

\section{Hasil dan Pembahasan}

Adapun data hasil penelitian yaitu berdasarkan tabel 1 diperoleh informasi bahwa dari 41 responden, sebagian besar yaitu 26 responden (63\%) memiliki pendidikan dasar, hampir setengahnya yaitu 13 responden (32\%) memiliki pendidikan menengah dan sebagian kecil yaitu dua responden $(5 \%)$ memiliki pendidikan tinggi. Berdasarkan tabel 2 di atas diperoleh informasi bahwa dari 41 responden, hampir setengahnya yaitu 18 responden (44\%) berumur 60-74 tahun, hampir setengahnya yaitu 14 responden (34\%) berumur antara 4959 tahun, hampir setengahnya yaitu sembilan responden (22\%) berumur 75-90 tahun, dan tidak ada responden yang berumur diatas 90 tahun. Berdasarkan tabel 3 diperoleh informasi bahwa dari 41 responden, sebagian besar 22 responden (54\%) mendapatkan sumber informasi dari petugas kesehatan, sebagian kecil yaitu 12 responden (29\%) mendapatkan sumber informasi dari media elektronik dan tujuh responden (17\%) mendapatkan sumber informasi dari media cetak.

Tabel 1. Distribusi Frekuensi Karakteristik Responden Berdasarkan Pendidikan di Dusun Mandung Desa Sembung Gede Tahun 2018

\begin{tabular}{llcc}
\hline No & Pendidikan Terakhir & Frekuensi (f) & Persentase (\%) \\
\hline 1. & Dasar & 26 & 63 \\
\hline 2. & Menengah & 13 & 32 \\
\hline 3. & Tinggi & 2 & 5 \\
\hline & Jumlah & 41 & 100 \\
\hline
\end{tabular}

Sumber: Data Primer Penelitian Desember 2018 
e-ISSN : 2614-5685

p-ISSN : 2614-5421

Tabel 2. Distribusi Frekuensi Karakteristik Responden Berdasarkan Umur di Dusun Mandung Desa Sembung Gede Tahun 2018

\begin{tabular}{clcc}
\hline No & Kelompok Umur & Frekuensi (f) & Presentasi (\%) \\
\hline 1. & $49-59$ tahun & 14 & 34 \\
\hline 2. & $60-74$ tahun & 18 & 44 \\
\hline 3. & $75-90$ tahun & 9 & 22 \\
\hline 4. & $>90$ tahun & 0 & 0 \\
\hline & Jumlah & 41 & 100 \\
\hline
\end{tabular}

Sumber: Data Primer Penelitian Desember 2018

Tabel 3. Distribusi Frekuensi Karakteristik Responden Berdasarkan Sumber Informasi di Dusun Mandung Desa Sembung Gede Tahun 2018

\begin{tabular}{llcc}
\hline No & Sumber Informasi & Frekuensi (f) & Persentase (\%) \\
\hline 1. & Media elektronik & 12 & 29 \\
\hline 2. & Media cetak & 7 & 17 \\
\hline 3. & Petugas kesehatan & 22 & 54 \\
\hline & Jumlah & 41 & 100 \\
\hline
\end{tabular}

Sumber: Data Primer Penelitian Desember 2018

Tabel 4. Pengetahuan Lansia Tentang Posyandu Lansia di Dusun Mandung Desa Sembung Gede Kecamatan Kerambitan Kabupaten Tabanan Tahun 2018

\begin{tabular}{llcc}
\hline No & Pengetahuan & Frekuensi (f) & Presentase (\%) \\
\hline 1. & Baik & 8 & 20 \\
\hline 2. & Cukup & 30 & 73 \\
\hline 3. & Kurang & 3 & 7 \\
\hline & Jumlah & 41 & 100 \\
\hline
\end{tabular}

Sumber: Data Primer Penelitian Tahun 2018

Tabel 5. Distribusi Frekuensi Pengetahuan Lansia Tentang Posyandu Lansia Berdasarkan Pendidikan di Dusun Mandung Desa Sembung Gede Tahun 2018

\begin{tabular}{|c|c|c|c|c|c|c|c|c|c|}
\hline \multirow[t]{3}{*}{ No } & \multirow[t]{3}{*}{ Pengetahuan } & \multicolumn{6}{|c|}{ Pendidikan } & \multirow{2}{*}{\multicolumn{2}{|c|}{ Total }} \\
\hline & & \multicolumn{2}{|l|}{ Dasar } & \multicolumn{2}{|c|}{ Menengah } & \multicolumn{2}{|c|}{ Tinggi } & & \\
\hline & & f & $\%$ & f & $\%$ & f & $\%$ & f & $\%$ \\
\hline 1. & Baik & 4 & 50 & 3 & 38 & 1 & 12 & 8 & 100 \\
\hline 2. & Cukup & 20 & 67 & 9 & 30 & 1 & 3 & 30 & 100 \\
\hline 3. & Kurang & 2 & 67 & 1 & 33 & 0 & 0 & 3 & 100 \\
\hline
\end{tabular}

Sumber: Data Primer Penelitian Tahun 2018 
Tabel 6. Distribusi Frekuensi Pengetahuan Lansia Tentang Posyandu Lansia Berdasarkan Umur di Dusun Mandung Desa Sembung Gede Tahun 2018

\begin{tabular}{|c|c|c|c|c|c|c|c|c|c|c|c|}
\hline \multirow[t]{3}{*}{ No } & \multirow[t]{3}{*}{ Pengetahuan } & \multicolumn{8}{|c|}{ Umur } & \multirow{2}{*}{\multicolumn{2}{|c|}{ Total }} \\
\hline & & \multicolumn{2}{|c|}{$\begin{array}{l}49-59 \\
\text { tahun }\end{array}$} & \multicolumn{2}{|c|}{$\begin{array}{l}\text { 60-74 } \\
\text { tahun }\end{array}$} & \multicolumn{2}{|c|}{$\begin{array}{l}75-90 \\
\text { tahun }\end{array}$} & \multicolumn{2}{|c|}{$\begin{array}{c}>90 \\
\text { Tahun }\end{array}$} & & \\
\hline & & f & $\%$ & $\mathbf{F}$ & $\%$ & f & $\%$ & f & $\%$ & $\mathbf{f}$ & $\%$ \\
\hline 1 & Baik & 3 & 37,5 & 4 & 50 & 1 & 12,5 & 0 & 0 & 8 & 100 \\
\hline 2 & Cukup & 11 & 37 & 13 & 43 & 6 & 20 & 0 & 0 & 30 & 100 \\
\hline 3 & Kurang & 0 & 0 & 1 & 33 & 2 & 67 & 0 & 0 & 3 & 100 \\
\hline
\end{tabular}

Sumber : Data Primer Penelitian Tahun 2018

Tabel 7. Distribusi Frekuensi Pengetahuan Lansia Tentang Posyandu Lansia Berdasarkan Sumber Informasi di Dusun Mandung Desa Sembung Gede Tahun 2018

\begin{tabular}{|c|c|c|c|c|c|c|c|c|c|}
\hline \multirow[t]{3}{*}{ No } & \multirow[t]{3}{*}{ Pengetahuan } & \multicolumn{6}{|c|}{ Sumber Informasi } & \multirow{2}{*}{\multicolumn{2}{|c|}{ Total }} \\
\hline & & \multicolumn{2}{|c|}{$\begin{array}{c}\text { Media } \\
\text { elektronik }\end{array}$} & \multicolumn{2}{|c|}{$\begin{array}{l}\text { Media } \\
\text { cetak }\end{array}$} & \multicolumn{2}{|c|}{$\begin{array}{c}\text { Petugas } \\
\text { kesehatan }\end{array}$} & & \\
\hline & & $f$ & $\%$ & $\mathrm{f}$ & $\%$ & $f$ & $\%$ & $\mathrm{f}$ & $\%$ \\
\hline 1 & Baik & 0 & 0 & 2 & 25 & 6 & 75 & 8 & 100 \\
\hline 2 & Cukup & 9 & 30 & 5 & 17 & 16 & 53 & 30 & 100 \\
\hline 3 & Kurang & 3 & 10 & 0 & 0 & 0 & 0 & 3 & 100 \\
\hline
\end{tabular}

Sumber : Data Primer Penelitian Tahun 2018

Pengetahuan lansia tentang posyandu diukur dengan menggunakan kuesioner yang terdiri dari 15 pernyataan. Hasil penelitian pada tabel 4 diperoleh informasi bahwa dari 41 responden, sebagian besar yaitu 30 responden (73\%) memiliki pengetahuan yang cukup, sebagian kecil yaitu delapan responden $(20 \%)$ pengetahuan yang baik dan sebagian kecil yaitu tiga responden $(7 \%)$ memiliki pengetahuan kurang.

Berdasarkan tabel 5 dari delapan responden yang memiliki pengetahuan baik, setengahnya yaitu empat responden $(50 \%)$ berpendidikan dasar, hampir setengah yaitu tiga responden $(38 \%)$ berpendidikan menengah dan sebagian kecil satu responden $(12 \%)$ berpendidikan tinggi. Dari 30 responden yang memiliki pengetahuan cukup, sebagian besar yaitu 20 responden $(67 \%)$ berpendidikan dasar, hampir setengahnya sembilan responden $(30 \%)$ berpendidikan menengah dan sebagian kecil satu responden (3\%) berpendidikan tinggi. Dari tiga responden yang memiliki pengetahuan kurang, sebagian besar yaitu dua responden (67\%) berpendidikan dasar dan hampir setengahnya yaitu satu responden (33\%) berpendidikan menengah dan tidak ada responden berpendidikan tinggi.

Berdasarkan tabel 6 dari delapan responden yang memiliki pengetahuan baik, setengahnya yaitu empat responden $(50 \%)$ berumur antara 60-74 tahun, hampir setengahnya tiga responden $(37,5 \%)$ berumur antara 49-59 tahun, sebagian kecil yaitu satu responden $(12,5 \%)$ berumur antara 75-90 tahun dan tidak ada responden berumur $>90$ tahun. Dari 30 responden yang memiliki pengetahuan cukup, hampir setengahnya yaitu 13 responden (43\%) berumur antara 60-74 tahun dan 11 responden (37\%) berumur antara 49-59 tahun, sebagian kecil yaitu enam responden $(20 \%)$ berumur antara 75-90 tahun dan tidak ada responden berumur $>90$ tahun. Dari tiga responden yang memiliki pengetahuan yang kurang, sebagian besar responden yaitu dua responden $(67 \%)$ berumur antara 75-90 tahun, hampir setengahnya yaitu satu responden (33\%) berumur antara 60-74 tahun dan tidak ada responden berumur $>90$ tahun.

Berdasarkan tabel 7 dari delapan responden yang memiliki pengetahuan baik, sebagian besar enam responden (75\%) mendapatkan sumber informasi dari petugas 
kesehatan dan sebagian kecil yaitu dua responden $(25 \%)$ mendapatkan sumber informasi dari media cetak dan tidak ada responden yang mendapatkan sumber informasi dari media elektronik. Dari 30 responden yang memiliki pengetahuan cukup, sebagian besar 16 responden (53\%) mendapatkan sumber informasi dari petugas kesehatan, hampir setengahnya sembilan responden $(30 \%)$ mendapatkan sumber informasi dari media elektronik dan lima responden (17\%) mendapatkan sumber informasi dari media cetak. Dari tiga responden yang memiliki pengetahuan kurang, seluruhnya responden mendapatkan sumber informasi dari media elektronik.

\section{Simpulan}

Berdasarkan hasil penelitian Pengetahuan Lansia Tentang Posyandu Lansia di Dusun Mandung Desa Sembung Gede Kecamatan Kerambitan Kabupaten Tabanan Tahun 2018 dengan jumlah responden sebanyak 41 orang dapat disimpulkan yaitu sebagian besar pengetahuan lansia kurang tentang posyandu lansia, sebagian besar lansia memiliki pengetahuan kurang berusia 75-90 tahun dan seluruhnya memiliki pengetahuan kurang mendapatkan sumber informasi dari media elektronik.

\section{Referensi}

Badan pusat statistik R.I. (2015). Statistik

Penduduk Lansia 2015. Jakarta: Badan Pusat Statistik R.I.

Susenas. Badan Pusat Statistik. (2012). Profil statistik kesehatan lansia. Jakarta : Badan Pusat Statistik.

Jayanti, T. E. (2017). Gambaran Pengetahuan Keluarga Tentang Posyandu Lansia di Kecamatan Kupitan Kabupaten Sijunjung Sumatra Barat. Skripsi, 18.

Mujahidullah. (2012). Keperawatan Gerontik. Jogjakarta : Pustaka Umum.

Nugroho. (2012). Keperawatan Gerontik dan Geriatrik, edisi 3. Jakarta:ECG. 